\title{
The Maze of Vasodilator Response Criteria
}

\author{
J. Menno Douwes $\cdot$ Rolf M. F. Berger
}

Published online: 26 November 2010

(C) The Author(s) 2010. This article is published with open access at Springerlink.com

With great interest we read the article of Barst et al. [1]. We agree with their statement that the definition of a positive acute vasodilator response in patients with pulmonary arterial hypertension (PAH) remains controversial. We believe it is very important to minimize this controversy and use uniform criteria when studying the acute pulmonary vasodilator response in patients with PAH.

In their article, Barst and coworkers defined acute response criteria based on a $20 \%$ or more decrease in mean pulmonary arterial pressure (mPAP) with no decrease in cardiac index, or on a $25 \%$ or more decrease in the pulmonary vascular resistance index (PVRI) with no decrease in cardiac index (the latter only in case of an unrestricted shunt at the ventricular or ductal level). We do not recognise these criteria from previously published reports. A review of the literature provides the following definitions of a positive response to acute pulmonary vasodilator tests:

1. An mPAP decrease of $20 \%$ or more, no decrease in cardiac index and no change or a decrease in the pulmonary-to-systemic vascular resistance ratio $[2,3]$

2. A decrease of more than $20 \%$ in both mPAP and PVRI $[4,6]$

3. A fall in total pulmonary resistance of more than $30 \%$ [7]

J. M. Douwes $(\square)$. R. M. F. Berger

Center for Congenital Heart Disease, Department of Paediatric

Cardiology, Beatrix Children's Hospital, University Medical

Center Groningen, P.O. Box 30.001, 9700 RB Groningen,

The Netherlands

e-mail: j.m.douwes@bkk.umcg.nl
4. A decrease in mPAP of $10 \mathrm{mmHg}$ or more, reaching an mPAP of $40 \mathrm{mmHg}$ or less and a normal cardiac output [5].

To our knowledge, the criteria used in the current article have not been published previously. The use of different response criteria in different studies results in different prevalences of acute vasodilator response and different predictive values for identifying long-term responders to calcium-channel blocker treatment and patients with improved survival [5].

Furthermore, as a result, data from these studies cannot be compared directly. For example, the prevalence of acute responders among children with PAH (42\%) is reported to be higher than among adults $(12-26 \%)[2,4,5]$. However, because the criteria used differed between children and adults, this comparison does not hold.

We commend Barst and coworkers for their success in comparing the use of different vasodilating agents (inhaled nitric oxide, oxygen, or the combination of the two) for vasodilator testing in children. However, the introduction again of new response criteria prohibits interpretation of these data in the perspective of previously published data.

It is not our intention to discourage the quest for new response criteria aimed at reaching better prediction of treatment effect or survival or at expanding its use to broader patient populations other than those with idiopathic PAH (iPAH) or familial PAH (FPAH). However, in view of the ongoing discussion on the optimal definition of acute response criteria, we strongly advocate presenting the use of new criteria in a manner comparative with the use of previously published criteria.

Open Access This article is distributed under the terms of the Creative Commons Attribution Noncommercial License which permits any noncommercial use, distribution, and reproduction in 
any medium, provided the original author(s) and source are credited.

\section{References}

1. Barst RJ, Agnoletti G, Fraisse A, Baldassarre J, Wessel DL, for the NO Diagnostic Study Group (2010) Vasodilator testing with nitric oxide and/or oxygen in pediatric pulmonary hypertension. Pediatr Cardiol 31(5):598-606

2. Barst RJ, Maislin G, Fishman AP (1999) Vasodilator therapy for primary pulmonary hypertension in children. Circulation 99: 1197-1208

3. Barst RJ (1986) Pharmacologically induced pulmonary vasodilatation in children and young adults with primary pulmonary hypertension. Chest 89:497-503
4. Rich S, Kaufmann E, Levy PS (1992) The effect of high doses of calcium-channel blockers on survival in primary pulmonary hypertension. N Engl J Med 327:76-81

5. Sitbon O, Humbert M, Jais X, Ioos V, Hamid AM, Provencher S, Garcia G, Parent F, Herve P, Simonneau G (2005) Long-term response to calcium-channel blockers in idiopathic pulmonary arterial hypertension. Circulation 111:3105-3111

6. Sitbon O, Humbert M, Jagot JL, Taravella O, Fartoukh M, Parent F, Herve P, Simonneau G (1998) Inhaled nitric oxide as a screening agent for safely identifying responders to oral calciumchannel blockers in primary pulmonary hypertension. Eur Respir $\mathbf{J}$ $12: 265-270$

7. Sitbon O, Brenot F, Denjean A, Bergeron A, Parent F, Azarian R, Herve P, Raffestin B, Simonneau G (1995) Inhaled nitric oxide as a screening vasodilator agent in primary pulmonary hypertension: a dose-response study and comparison with prostacyclin. Am J Respir Crit Care Med 151:384-389 